\title{
Big history and the \\ cosmic perspective
}

\author{
lan Crawford summarizes an \\ interdisciplinary meeting on \\ scientific and social themes \\ related to astrobiology, big history \\ and cosmic perspectives.
}

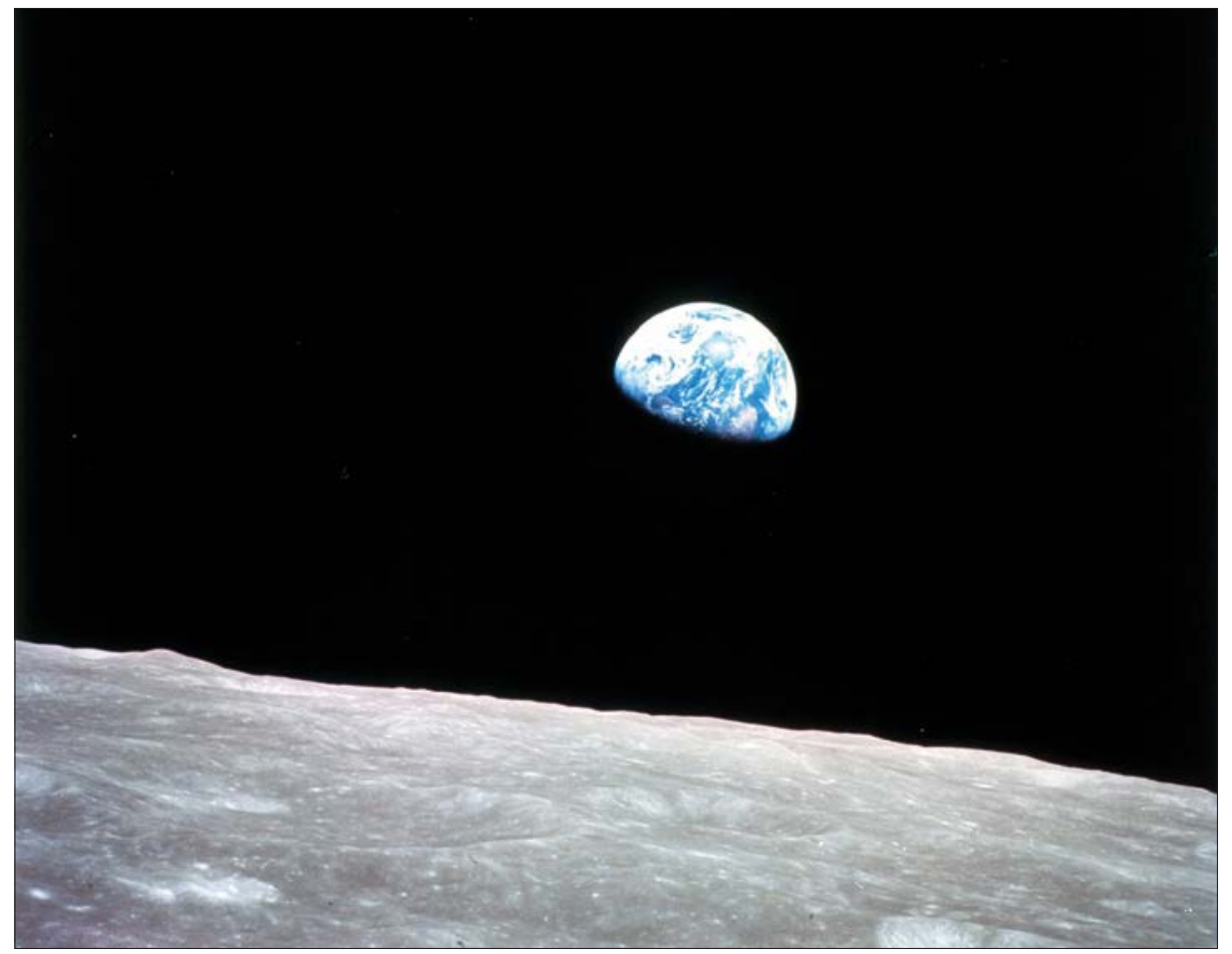

1 Images such as Earthrise, photographed from Apollo 8 in 1968, provide a cosmic perspective. (NASA)

comfort zone of theoretical physics to make highly productive speculations on the origin of life (Schrödinger 1944), Christian stressed the many intellectual benefits of interdisciplinary research and the unifying perspectives that can result. In particular, he noted that all human societies have felt Christian argued that such a perspective may be necessary if humanity is to find unified responses to urgent global challenges, not least those associated with human dominance of the Earth's environment in the Anthropocene epoch. Realizing these benefits, however, will require specialists the need of "origin stories" to _............ in different fields to follow orientate themselves in time "Teaching world history, Schrödinger's example and and space.

Summarizing the argument developed in his recent and indeed big history, could help counter nationalistic trends" be prepared to work across disciplines. As he put it during his talk: "It's worth taking the risk of interdisciplinary book (Christian 2018), he showed that it is now possible to provide a scientifically accurate origin story for the 21st century by integrating results from astronomy, geology, biochemistry, evolutionary biology, anthropology, history and other academic disciplines traditionally considered to be separate. It is the aim of big history to provide just such a unified view of cosmic and human history. The resulting unified perspective would help unite disparate scientific disciplines and thereby stimulate new scientific insights; it may also help heal the rift between the sciences and humanities identified by the scientist and novelist CP Snow (1959). Moreover, research because the payoff could be colossal." During the ensuing discussion, Christian also drew attention to the deleterious consequences of teaching narrow national histories in schools, serving to reinforce nationalism, and argued that teaching world history, and indeed big history, could help counter nationalistic trends.

\section{Evolution and ethics}

The second talk was given by Marnie Hughes-Warrington (ANU) on "Does big history imply the need to rescale ethics?" She began by explaining that, as a historiographer, the opportunity to study the 
appearance of a new field like big history is of interest in itself. However, she pointed out that big history actually forms part of a long tradition of universal histories dating back to the ancient world; she drew particular attention to Diodorus Siculus's Library of History, which dates from the first century BCE. Hughes-Warrington pointed out that this type of history fell out of favour in the 19th century, but that it is now making a comeback in the form of big history. She then noted that there is no standard scale for histories, and that this arises from the interest of historians in describing how the world ought to be, and not just how it has been. As big historians have expanded both the range of phenomena described and the disciplines that might contribute to the description of those phenomena, an opportunity to rescale ethics has opened up. Christian used the example of the Nazca lines to highlight how we might have two scale views of the same phenomena: we can see rocks on the ground, and we can see a picture from space. So, too, different histories can highlight whether the actions of humans towards one another are good, fair or right, or whether the rise of cyanobacteria should be seen as an evolutionary leap forward or an "oxygen holocaust" (Margulis \& Sagan 1997), or whether the big history description of humans as "planetary managers" suggests responsibility for environmental change. These various views of phenomena may be different in degree or kind, and that might suggest ethical scales that are also different in degree and kind. HughesWarrington suggested that metaphysical analysis would seem to indicate that they were differences in degree, and that the scales of ethics implied in big histories might be extensions of existing ethical theories, rather than entirely new ones.

Elise Bohan (Macquarie University) concluded the first session, dedicated specifically to big history, with her talk on "Why big history matters". She argued that big history is a powerful narrative that promotes scientific literacy and big picture thinking, encourages rational decision making, and exposes more humans than ever to "the magic of reality". If taught globally, especially to young people, it can provide a much needed scientific view of reality to millions of students whose engagement with science has been minimal or non-existent. She invited participants to consider a list of the 10 most important things that any educated person should know, including knowledge of the laws of physics, evolution, climate change and the history of humanity; she argued that teaching big history in schools has the potential to lay the foundations of such broadly based knowledge among the wider public.

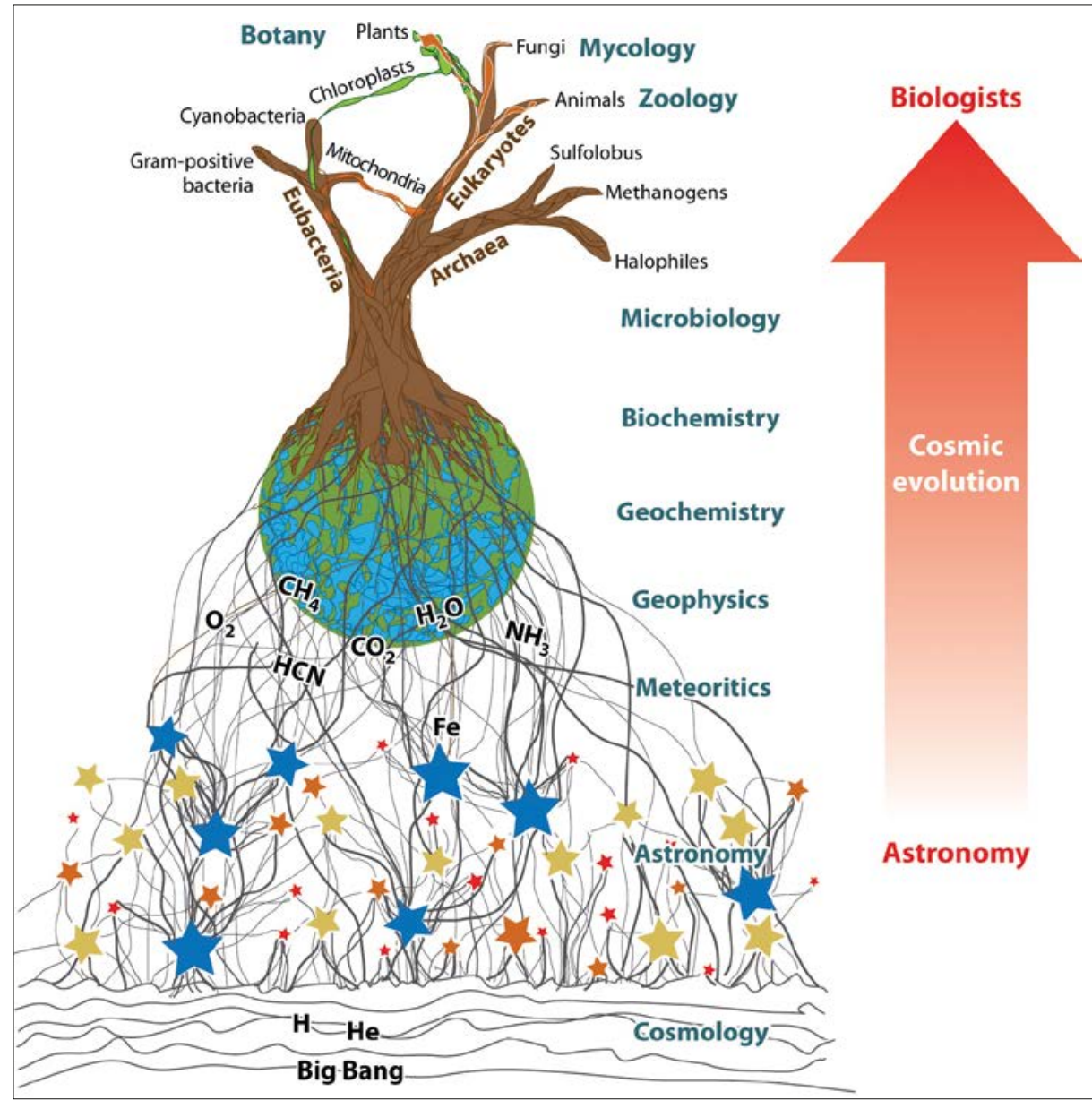

2 A schematic evolutionary tree for life on Earth, with its roots extending back to the Big Bang. Note the wide range of different academic disciplines involved in constructing this evolutionary history. (Reproduced with permission from Lineweaver and Chopra 2012)

Stressing a point already made by Christian, Bohan also argued that big history does a tremendous job of orienting modern humans existentially and tribally, at a time when national and traditional narratives are increasingly being challenged and rewritten. In a globalized world, she argued that big history shows us that family and community are still as important as ever, but that our tribe is actually much bigger than we used to imagine. For these reasons, and based on her own experience teaching big history to university students, Bohan concluded that the big history story has significant power to change the world for the better.

\section{Fake universes}

After the coffee break, the discussion moved towards more theoretical considerations. Paul Davies (Arizona State University, USA) asked the intriguing question "Is the universe a fake?" He began by noting that the question of "truth" bedevils all studies of history, including big history - is what we believe to be historical fact really an accurate description, or just a mass of competing narratives and interpretations? This uncertainty is greatly magnified if, following Descartes, we allow for the possibility that what we think of as reality might itself be an illusion.

Davies noted that some computer scientists claim to be on the verge of simulating consciousness, raising the possibility that ............. we might ourselves soon be Societies tend to think able to create simulated realities for simulated consciousnesses. How can we be sure that the same isn't being done to us (e.g. Bostrom 2003)? As
erses are presumably easier to "fake" universes are presumably easier to
create than "real" ones, any given observer is more likely to exist in one of the former, and the advent of quantum computing is only likely to make the generation of simulated realities easier. Moreover, many scientists now favour some version of the so-called multiverse theory, which posits a vast number of parallel universes having different physical laws. This may account for why our universe is apparently fine-tuned for life because, by definition, life could only arise in that subset of universes where the physical laws permit it (e.g. Davies 2006). However, if multiple universes exist then it seems inevitable that simulated universes will have been created somewhere, so the problem of distinguishing real from simulated universes remains. 
Davies argued that the only way to tell whether we live in a real or a fake universe would be to observe apparent inconsistencies in Nature owing to an imperfect simulation - e.g. "can we observe the scenery wobbling?" He then noted that the technology required for the simulation of reality might also explain the lack of evidence for intelligent life elsewhere in our universe, summarized in the Fermi paradox: any sufficiently advanced life may prefer to retreat into post-biological existences in simulated worlds. However, Davies concluded with a warning from a big historical perspective: societies have tended to think about the universe in terms of the dominant technology of their time, successively as a musical instrument, a clockwork mechanism, a giant steam engine and now a sophisticated computer simulation. As technology moves on, our current fascination with computationally created realities may come to seem naïve.

\section{Entropy as hero}

Davies was followed by Charley

Lineweaver (ANU) who spoke on "Useful lies and cosmic perspectives." In this wide-ranging talk, he made the important point that brains (like livers and lungs) are organs that have been selected to keep us alive and reproduce. Brains have been selected to support useful cosmic perspectives, not necessarily truthful ones. If true ideas are useful, selection will favour brains that harbour them. If false ideas are useful, brains that harbour them will also be selected for. In this Darwinian view, our cosmic perspectives (answering such questions as "who are we?" and "what is our place in the universe?") should be useful, but not necessarily truthful.

Fortunately, there is an overlap between "useful" and "true" perspectives, and the scientific method falls within this category. Lineweaver quoted EO Wilson (2013): "The scientific method has been consistently better than religious beliefs in explaining the origin and meaning of humanity," but challenged the view that science is a search for truth. He suggested rather that science, like any worldview, is constrained by the need to be useful. Lineweaver argued that some commonly held aspects of the scientific worldview, such as imagined trends towards increasing complexity and suggestions that the human brain is the most complicated structure in the universe, are not supported by objective assessments of the data.

Moreover, contrary to some popular representations of big history, Lineweaver argued that if we have to anthropomorphize the increase of entropy, it should be as "hero", not "villain", because all life forms and all far-from-equilibrium dissipative structures have been produced to increase entropy production. He proposed a paradigm shift from "We eat food?" to "Food has produced us to eat it". Following these theoretical observations, Lineweaver drew attention to some negative consequences of human tribalism, for example the recent controversies regarding dual nationality in the Australian parliament, and pointed out that cultural diversity should be celebrated, not denigrated. A big historical perspective ........ would promote, not stigscientific matize, dual citizenship in governments.

After lunch, Naomi McClure-Griffiths (ANU) spoke on "The cosmic

perspective of a galactic astronomer", providing an astronomical overview of our location in the universe. She pointed out that for centuries humans have struggled to reconcile the Moon, stars and planets as external to the Earth, and that this growing realization pushed the human-centric worldview into a new realm where we had to accept that we are not the centre of the universe. The past century has shaken our worldview even more. Not only have we realized that our Milky Way galaxy is one of many, but that our place within the Milky Way is not special either. One might even go so far as to describe our location as boring: a bog-standard star in the suburban wastelands of a bog-standard galaxy. Perhaps even more significantly, the discovery within the last 20 years that planets are common companions of stars has shown us that even planet Earth may not be special in a cosmic context. All this has resulted in a "lost sense of specialness" for humanity. However, while on one level this might tend to make us despondent, McClure-Griffiths argued that there is a deeper ethical, or even practical, implication: the universe is so large, and we are such tiny components of it, that the only things that really matter are our interactions with each other. It will not matter to the universe if we destroy ourselves, or even if we render the Earth uninhabitable, but it matters to us, and this perspective may help guide our actions.

\section{The truth is not enough}

McClure-Griffiths was followed by Mark Lupisella (The Horizons Project, http:// horizonsproject.org) who asked "Is the universe enough? Can it suffice as a basis for satisfactory worldviews?" He argued that worldviews are important because they drive how people believe, think and act, but also that they can be dangerously misguided. Modern science can inform more truthful worldviews, but although the scientific perspective is unique and compelling, we need to recognize that it may not be enough for everyone. Contemplating the modern scientific universe can be humbling and awe-inspiring, even motivating, but it can also be unsettling and uncertain, even scary. The extent to which the universe we know today can form the basis of satisfying worldviews rests in large part on human psychology, preferences and needs. Many of these human predispositions may have deep evolutionary roots that we need to be aware of. For example, a predisposition to believe in a personal deity may have arisen as a result of natural selection during human evolution; certain scientific cosmic perspectives, even if "true", may have difficulty in satisfying this and other important psychological needs, such as guiding human behaviour, coping with death, etc. In short, Lupisella argued that scientifically informed cosmic perspectives might be sufficient "for some people some of the time, but probably not for most people most of the time". Although he added the caveat that future humans or our artificial intelligence descendants, as well as other forms of intelligence that may exist in the universe, might be more receptive to "cosmic worldviews".

Lupisella argued that if we are not satisfied with worldviews we have today, then we should keep working to develop new ones that could have the potential to be useful and satisfying. One possible direction might be to explore relationships between cosmic evolution and cultural evolution. One attractive aspect of such cosmocultural worldviews is the insight that, through biological and cultural evolution, the universe has seemingly "bootstrapped" itself into the realm of values, meaning and purpose, even if these did not exist from the beginning (Lupisella 2009). These ideas are developed further in a forthcoming book (Lupisella 2018).

The evolutionary theme was continued by John Stewart (Free University of Brussels, Belgium) who discussed "How the future trajectory of evolution reveals a meaningful role for humanity". He argued that an understanding of the large-scale evolutionary processes that have formed humanity, and that will shape our future, is capable of providing meaning and purpose for human existence. This follows from the realization that the evolution of life on Earth has a trajectory: evolution has moved in the direction of producing cooperative organizations of increasing scale and evolvability (Stewart 2000, 2014). Stewart argued that the benefits of cooperation and evolvability that have driven this trajectory will continue to operate into the future on yet larger scales, and that they favour the emergence of a cooperative organization on the scale of the planet that will eventually expand 
into space. Indeed, he maintained that this trajectory will manifest on any planet on which life emerges, with the resultant planetary organizations linking cooperatively at larger and larger astronomical scales.

Crucially, while this trajectory towards increasing cooperation is initially driven by natural selection, after a certain point it will continue only if it is driven intentionally by a sentient organism such as humanity. Such an organism will face a fundamental existential choice once it becomes aware of its potential role in advancing the trajectory of evolution: either it commits to intentionally driving the process forward and participating positively in the future evolution of life in the cosmos, or it turns its back on life and continues to squat on the planet on which it arose, satisfying Stone Age desires until its inevitable demise.

\section{Better together}

Following the tea break, the discussion moved on towards societal and political implications, and to this end Chris Hamer (University of New South Wales, Australia) discussed "The evolution of Earth federation from a cosmic perspective". The cosmic perspective makes it abundantly clear we are all citizens of the one small planet and that we all face some major global challenges. Some of these, such as climate change and nuclear weapons, may even threaten the future of our civilization. These global problems need global solutions and Hamer argued that a system of democratic global governance, empowered to make binding laws and regulations to deal with these global issues, would be the most sensible way to deal with these problems. World federation would be one possible solution and he reviewed some of the history of world federalist concepts (Hamer 1998, see also Leinen \& Bummel 2018).

Hamer noted that, historically, the concept of world federalism has often gone hand-in-hand with cosmic and big historical worldviews. For example, HG Wells, plausibly "the godfather of big history", was also a leading proponent of world government, observing in his Outline of History that "there can be little question that the attainment of a federation of all humanity ... would mean such a release and increase of human energy as to open a new phase in human history" (Wells 1920). The same connection has also been made in fiction: in the popular science fiction series Star Trek, for example, world federation occurs in the 22nd century, before being extended to other planetary

civilizations, possibly prefiguring the increasing scale of societal evolution predicted by Stewart.

Despite the anticipated benefits, realizing world federation will of course be very difficult from the point of view of practical politics and, after reviewing some options, Hamer argued that Europe has shown the way, with the stage-by-stage evolution of the European Union, and has developed the basic principles upon which an Earth Federation could be based. He suggested, following Clarence Streit (1939), that the next most practical step would be a world security community of democratic nations.

The final talk was given by Ian Crawford (Birkbeck College/ANU) who attempted to connect a number of strands with his talk on "Widening perspectives: the intellectual and social benefits of astrobiology, big history, and the exploration of space". He began by making the link between big history and the still relatively new discipline of astrobiology. Astrobiology is usually defined as the study of the origin, evolution, distribution and future of life in the universe. As such it is inherently interdisciplinary and cannot help but engender a worldview infused by cosmic and evolutionary perspectives similar to those implicit in big history. Crawford demonstrated this link through a personal anecdote: a large part of the astrobiology module that he teaches at Birkbeck College is based on an earlier course entitled "Cosmic perspectives for world history" that he devised for the City University's extramural programme in 1994.

In agreement with other speakers, Crawford argued that big history and astrobiology are both acting to widen human perspectives in beneficial directions (see Crawford 2018). These include stimulating the (partial) reintegration of scientific disciplines after a period of extreme specialization, breaking down some of the barriers between the sciences and the humanities identified by Snow (1959), and enhancing public awareness of cosmic and evolutionary perspectives which comprise a strong, if implicit, argument for the political unification of humanity. He agreed with Hamer that a world federation would be an appropriate political means of implementing the latter. Crawford concluded by noting that astrobiology and big history are also concerned with the future of humanity, and he argued that space exploration will enable a richer future than will be attainable if humanity remains Earth-bound. In addition to the scientific benefits of space exploration (including a central role for astrobiology), he argued that two important societal benefits will also follow: (i) a visceral reinforcing of the cosmic perspective that astrobiology and big history can only provide intellectually (see also White 2014); and (ii) a vast expansion of the horizons of human experience and correspondingly increased exposure to a wide range of intellectual and cultural stimuli not otherwise attainable (e.g. Crawford 2014).

Overall, the meeting successfully demonstrated the interconnections between the eclectic set of topics discussed and, albeit in a small way, was helpful in forging links between disparate disciplines as advocated by Snow (1959). From the perspective of the hard sciences, here represented by astronomy, astrobiology and cosmology, perhaps the major take-home message was that these sciences, working with the humanities, have the potential to yield significant societal benefits by informing cosmopolitan worldviews among the global public. Based on this experience, the organization of similar interdisciplinary meetings in the future would be desirable. $\bullet$

\section{AUTHOR \\ Ian Crawford is professor of planetary science and astrobiology at Birkbeck, University of London, UK, and visiting fellow at the Australian National University.}

\section{ACKNOWLEDGMENTS}

I thank all the speakers for contributing to this interesting meeting. The summaries given here are based on the authors' submitted abstracts and my own notes. I accept responsibility for any errors in interpretation. I thank the Humanities Research Centre at the Australian National University, and especially Prof. Will Christie and Penny Brew, for hosting the meeting and for their hospitality during my all-too-brief stay as a visiting fellow.

\section{REFERENCES}

Bostrom N 2003 Philosophical Quarterly 53243 Christian D 2004 Maps of Time: an Introduction to Big History (University of California Press, Berkeley) Christian D 2018 Origin Story: a Big History of Everything (Penguin, London)

Crawford I A 2014 J. Brit. Interplanetary Soc. 67253 Crawford IA 2018 Int. J. Astrobiol. 1757

Davies P 2006 The Goldilocks Enigma: Why is the Universe Just Right for Life? (Allen Lane, London) Hamer C 1998 A Global Parliament: Principles of World Federation (CreateSpace) Leinen J \& Bummel A 2018 A World Parliament: Governance and Democracy in the 21st Century (Democracy Without Borders, Berlin) Lineweaver CH \& Chopra A 2012 Ann. Rev. Earth

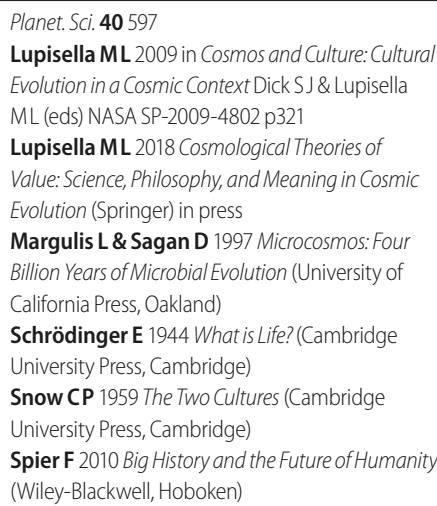

Stewart J 2000 Evolution's Arrow: the Direction and Evolution and the Future of Humanity (Chapman Press, Canberra)

Stewart J 2014 Biosystems 12327 Streit C 1939 Union Now: a Proposal for a Federal Union of the Leading Democracies (Jonathan Cape, London)

Wells HG 1920 The Outline of History (George Newnes, London) White F 2014 The Overview Effect: Space Exploration and Human Evolution (Library of Flight, American Institute of Aeronautics and Astronautics, Reston)

Wilson EO 2013 Letters to a Young Scientist (Liveright, New York) 